Check for updates

Cite this: RSC Adv., 2019, 9, 24951

\title{
Compound reinforcement of glaze wear resistance by prestress and second grain phase
}

\begin{abstract}
Yougen $\mathrm{Yu}^{\mathrm{a}}{ }^{\mathrm{H}}$ Huazhi Su, ${ }^{\mathrm{b}}$ Kang Guan, ${ }^{\mathrm{a}}$ Cheng Peng ${ }^{\mathrm{a}}$ and Jianqing Wu (DD *a
To study the reinforcement effect of prestress and hard grains on glaze wear resistance, fused quartz was added to a ceramic body to introduce various prestresses by creating a thermal expansivity difference with glaze, and feldspar opaque glazes with and without zircon grains were coated on the ceramic bodies. The elastic moduli and Poisson ratios of the glazes were measured by the 2D-DIC system. Furthermore, the prestress of the glaze was calculated according to the double-layer thermal residual stress model and measured by DIC using the stress-release method. The weight losses of the samples caused by the modified method of ISO 10545-7 were determined; the results showed that the weight of the glaze was reduced by $23.8 \%$ by increasing the prestress to $81.2 \mathrm{MPa}$ and by $35.9 \%$ by adding $7.2 \mathrm{wt} \%$ zircon grains. By introducing $7.2 \mathrm{wt} \%$ zircon grains and enhancing the prestress to $123.7 \mathrm{MPa}$, the abrasion weight loss was decreased by $62.7 \%$.
\end{abstract}

Received 7th June 2019

Accepted 26th July 2019

DOI: $10.1039 / \mathrm{c} 9 \mathrm{ra04279b}$

rsc.li/rsc-advances

involves tempering; ${ }^{21,22}$ the toughening treatment imposes a pressure stress on the surface of the products. However, pressure stress generated by the low thermal expansion of a glaze than that of the ceramic body exists in majority of glazed products. Higher prestress might help to further improve the grain glaze wear resistance. However, to date, limited studies have been conducted on the effect of pressure stress on the glaze wear resistance. Furthermore, it is difficult to evaluate the value of the pressure stress of glazed tiles, which is related to the elastic modulus and Poisson's ratio of the glaze and ceramic body. Note that to date, only few studies have investigated the elastic properties of glaze. High-temperature fluidity and the gas release process of a glaze confine the preparation of glazes with sizes suitable for the traditional bending method and the vibration method for the testing of Young's modulus. ${ }^{23,24}$ Although the compression test can directly measure the monolithic Young's modulus of samples with a strain gauge, to satisfy the fitting of most of the strain gauges, the samples should have a regular columnar shape and should be longer than $100 \mathrm{~mm}$. However, glazed samples with length more than $25 \mathrm{~mm}$ are difficult to prepare using a precision saw; moreover, the surfaces of some glazed samples may be matte or rough; this further makes it unlikely to obtain accurate results for strain gauges.

The abovementioned limitations have led to the introduction of a new technique called digital image correlation (DIC); DIC $^{25,26}$ is a fast, accurate, non-contact and non-destructive optical technique that can measure accurate displacements and calculate the strains on the surface of a specimen subjected to a driving force with the help of a speckle pattern placed on the test surface of the specimens. A camera with high SNR (signal to noise ratio) is used to obtain the images of the surface of specimens both with and without various loading conditions. Subsequently, the deformation of the speckle pattern in the

${ }^{a}$ School of Materials Science and Engineering, South China University of Technology, Guangzhou 510640, Guangdong, China.E-mail: ceramicgroup@163.com

${ }^{b}$ Foshan Daqian Ceramic Pigment \& Glaze Co. Ltd., Foshan 528000, Guangdong, China 
selected region is tracked by comparing the images via the DIC analysis software. Finally, the strain on the surface is calculated.

In this study, a consumer-grade high-SNR camera was used to obtain the images of the specimens with and without various compression loadings. In addition, the 2D-DIC software was used to analyze the lateral and the axial strain on the specimens. Thus, the Young's modulus and Poisson's ratio of the specimens could be easily and accurately measured. Furthermore, a calculation model to evaluate the glaze stress generated by the cooling shrinkage was introduced, and the prestress of the glaze was measured by DIC using a stress-release method. Finally, both individual and collective effects of the prestress and zircon grains on the wear resistance of the glazed tile were investigated.

\section{Experimental procedure}

\subsection{Sample preparation}

Commercial green tile powder (YLW, H80244X, CHN) with and without various amounts of fused quartz $(\mathrm{D} 50=18 \mu \mathrm{m})$ was used to prepare ceramic bodies with different thermal expansivity values. The green powder and fused quartz were mixed with a certain amount of water in a planetary mill. After drying, the mixture was granulated by passing it through a 20-mesh sieve, and then, the granulated powder was compressed to square green bodies with the side length of $110 \mathrm{~mm}$. Herein, four kinds of ceramic bodies were prepared and labeled as $\mathrm{R}_{0}$, $\mathrm{R}_{3}, \mathrm{R}_{10}$ and $\mathrm{R}_{15}$, which contained $0 \mathrm{wt} \%, 3 \mathrm{wt} \%, 10 \mathrm{wt} \%$ and $15 \mathrm{wt} \%$ of fused quartz, respectively.

To investigate the effect of prestress and zircon grains on the wear resistance of glaze, two kinds of glazes that were adaptable to the firing schedule of a roller kiln were prepared: one was feldspar opaque glaze with zircon grains, marked as $\mathrm{G}_{1}$, and the other was feldspar opaque glaze, marked as $\mathrm{G}_{2}$. The raw materials consisted of alumina, zircon, kaolin, calcite, albite, talc, barium carbonate and zinc oxide, and the compositions of these two glazes are listed in Table 1 . After being passed through a 200-mesh sieve, the raw materials were mixed with a certain amount of water, $0.3 \mathrm{wt} \%$ sodium carboxymethyl cellulose (CMC), and $0.3 \mathrm{wt} \%$ sodium tripolyphosphate (STP) followed by milling in the planetary mill for $30 \mathrm{~min}$. Then, the slurry was sprayed onto the green bodies. The thickness of the glazes was controlled by the weight gain of the ceramic bodies. To study the influence of thermal expansivity on the glaze wear resistance, approximately $10 \mathrm{~g}$ of $\mathrm{G}_{1}$ and $\mathrm{G}_{2}$ slurries were sprayed on the $7 \mathrm{~mm}$-thick samples $\mathrm{R}_{0}, \mathrm{R}_{3}, \mathrm{R}_{10}$ and $\mathrm{R}_{15}$, which were marked as $R_{0}-G_{1}-R_{15}-G_{1}$ and $R_{0}-G_{2}-R_{15}-G_{2}$, respectively. To investigate the effect of the thickness ratio (glaze/ceramic body) on the glaze wear resistance, approximately $8 \mathrm{~g}, 10 \mathrm{~g}$ and $12 \mathrm{~g}$ of $\mathrm{G}_{2}$ slurries were sprayed onto 6,7 and $8 \mathrm{~mm}$ thick $\mathrm{R}_{0}$, and the obtained samples were marked as $\mathrm{R}_{06}{ }^{8}-\mathrm{R}_{08}{ }^{12}$. The subscript represents the thickness of $R_{0}$, and the superscript represents the mass of the $\mathrm{G}_{2}$ slurry.

After drying, the samples were thermally treated in a roller kiln at $1200{ }^{\circ} \mathrm{C}$ at the heating rate of $40{ }^{\circ} \mathrm{C} \mathrm{min}{ }^{-1}$, where they were held for $5 \mathrm{~min}$ at maximum temperature and then subjected to the average cooling rate of $50{ }^{\circ} \mathrm{C} \mathrm{min}^{-1}$. The glaze surfaces were analyzed after firing.
Table 1 Compositions of $G_{1}$ and $G_{2}$ (wt\%)

\begin{tabular}{lllllllll}
\hline Numb. & $\mathrm{SiO}_{2}$ & $\mathrm{Al}_{2} \mathrm{O}_{3}$ & $\mathrm{CaO}$ & $\mathrm{ZnO}$ & $\mathrm{MgO}$ & $\mathrm{Na}_{2} \mathrm{O}$ & $\mathrm{ZrO}_{2}$ & $\mathrm{BaO}$ \\
\hline $\mathrm{G}_{1}$ & 51.13 & 17.76 & 7.76 & 2.83 & 6.33 & 4.75 & 4.79 & 4.65 \\
$\mathrm{G}_{2}$ & 49.74 & 19.22 & 9.98 & 3.68 & 3.34 & 7.34 & 0.00 & 6.70 \\
\hline
\end{tabular}

To investigate thermal expansivity, elastic modulus and Poisson's ratio, the glaze slurry was dried and granulated by passing it through a 20-mesh sieve and then compressed into glazed bodies. These glazed bodies were placed on a corundum gasket and fired at $1200{ }^{\circ} \mathrm{C}$ for a certain period of time $\left(30 \mathrm{~min}\right.$ for $\mathrm{G}_{1}$ and $60 \mathrm{~min}$ for $\mathrm{G}_{2}$ ) to eliminate air bubbles resulting from the thick glaze layer. After firing, these hemispherical specimens were cut into cuboids and annealed at $600{ }^{\circ} \mathrm{C}$ for $2 \mathrm{~h}$. The ceramic bodies were also cut into cuboids for the test.

\subsection{Characterization techniques}

X-ray diffraction (XRD; PANalytical X'pert PRO, Almelo, the Netherlands) using $\mathrm{Cu} \mathrm{K} \alpha$ radiation from $10^{\circ}$ to $60^{\circ}$ with the step of $0.03^{\circ}$ and the time step of $0.1 \mathrm{~s}$ was used to verify the crystalline phase of the glazes. Scanning electron microscopy (SEM; ZEISS EVO 18, Oberkochen, Germany) was used to observe the micromorphology of the samples in the back-scattered electron (BSE) pattern and secondary electron (SE) pattern. Samples were etched by a 1 vol\% hydrofluoric acid solution for $1 \mathrm{~min}$ before observation. The thermal expansion of the samples was measured by a thermodilatometer (DIL 402 Expedis Classic) with the size of $3 \times$ $3 \times$ more than $25 \mathrm{~mm}$. The Archimedes principle was employed to measure the water absorption of the samples.

The established 2D-DIC system, an image of a specimen with speckle pattern and the testing machine are shown in Fig. 1. The DIC system consisted of a CMOS industrial camera (SunTae, MX880M, CHN, 8.8 megapixel, $2.5 \mu \mathrm{m}$ pixel), one light source, one tripod stand and a PC workstation. A black spray was used to prepare a random speckled surface. The camera obtained the surface images of the specimens under various compressive loadings at the rate of $20.9 \mathrm{fps}$. The compressive loading was applied by a universal testing machine (Model 5567, Instron, USA). The open source software Ncorr V1.2 was used to process the obtained speckle pattern images. The subset radius of the region of interest (ROI) was set to 21-36 pixels, and the subset spacing was set to 1-3 pixels.

The wear resistance of the samples was characterized using a method modified based on the testing conditions of ISO 10545-7 (Ceramic tiles - part 7: Determination of resistance to surface abrasion for glazed tiles). After being weighed, the samples were cut to approximately $100 \times$ $100 \mathrm{~mm}$ and fixed under metal holders for the test. A standardized abrasive slurry obtained from ISO 10545-7, which contained steel balls with various diameters, aluminum oxide and distilled water, was poured into the holders as the abrasive. The system was rotated with the eccentricity of $22.5 \mathrm{~mm}$ at $300 \mathrm{rpm}$, and the applied revolutions of the abrasive slurry were 8000 rounds. After drying, the weight 


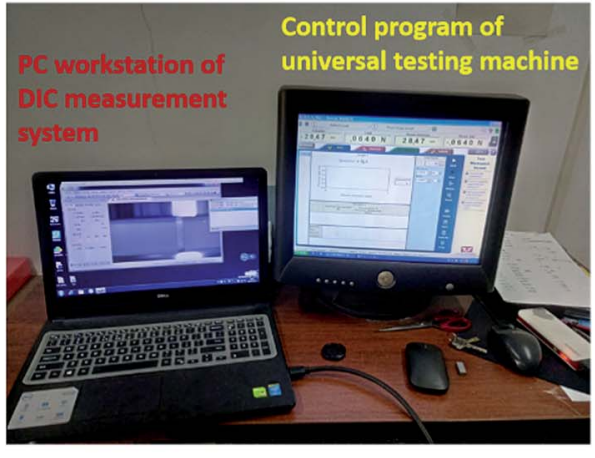

(a)

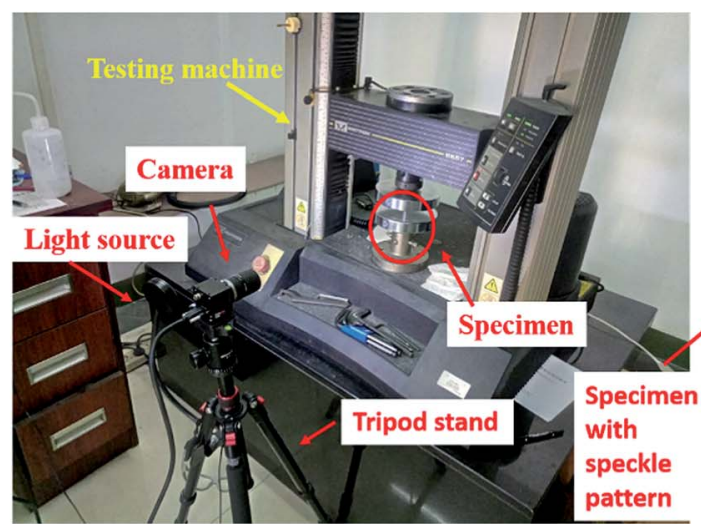

(b)
Compressive load

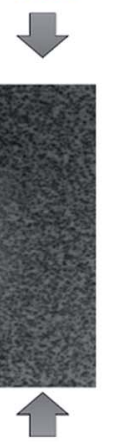

(c)

Fig. 1 2D-DIC system testing machine and specimen with a speckle pattern ((a) control platform; (b) working platform; (c) specimen with speckle pattern).

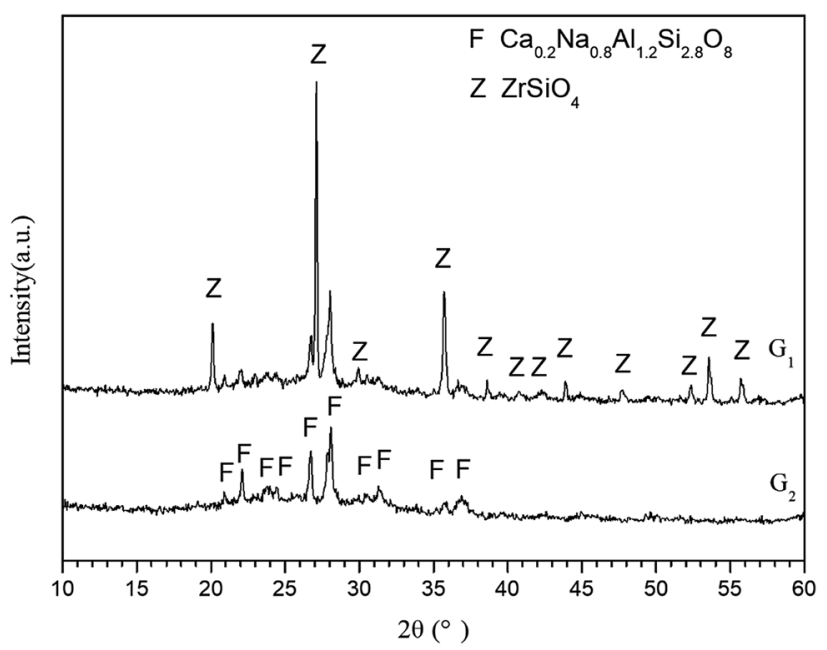

Fig. 2 XRD patterns of $G_{1}$ and $G_{2}$.

loss of six specimens of one sample was determined by an analytical balance (Sartorius, GL623, Max $620 \mathrm{~g}, d=1 \mathrm{mg}$ ).

For the measurement of prestress, the iron-zircon pigment at the water-material ratio of $1: 3$ was used as a dye, and the random feature points were printed on the surfaces of the samples by cotton. After drying, the fixed industrial camera was used to obtain the image of the initial state of the sample surface in an immobile position. Then, the sample was annealed at $700{ }^{\circ} \mathrm{C}$ for 2 hours. After obtaining the surface image of the annealed state, the surface stress was released via the slitting method. Finally, after the slitting process, the surface image of the sample was obtained, and then, the surface strain was analyzed by the 2D-DIC system. Therefore, the corresponding stress value was determined in accordance with the elastic modulus of the glaze.

\section{Results and discussion}

\subsection{XRD characterization of glazes}

The XRD patterns of $G_{1}$ and $G_{2}$ are shown in Fig. 2. Only the feldspar phase $\mathrm{Ca}_{0.2} \mathrm{Na}_{0.8} \mathrm{AlSi}_{1.2} \mathrm{O}_{8}$ existed in $\mathrm{G}_{2}$, whereas zircon and feldspar coexisted in $\mathrm{G}_{1}$. As zircon grains are widely used to enhance the wear resistance of glazed tiles, in this study, glazes both with and without zircon have been used to investigate the role of zircon grains in enhancing the wear resistance of glazes.

\subsection{Elastic modulus measurement of the glaze}

Fig. 3 shows the lateral and axial strain data plots of the $\mathrm{R}_{0}$ obtained in this study under the $15000 \mathrm{~N}$ compressive loading; these data plots consisted of a strain field contour in the specified direction, the key parameters set through the DIC analysis and the monolithic average strain under the specified load in the specified direction, as highlighted by the red frame. As shown in Fig. 3, in addition to the monolithic strains of the samples under compressive loads, the strain concentration regions of specimens under compressive loads could be clearly detected in the strain field contour.

The stress could be calculated by the load and the sectional area of the samples, and the lateral and axial strains of the samples under various loads could be tested by the DIC measurement. Consequently, the stress-strain curves and the lateral-axial strain curves were obtained, as shown in Fig. 4.

Herein, four compressive loads were applied for each sample, and the slopes of the stress-strain curves and the lateral-axial strain curves provided the elastic modulus and Poisson's ratio of the sample, respectively. All the correlation coefficients $R^{2}$ of the linear fittings for the curves were greater than 0.95 , suggesting that the 2 D-DIC system was competent to provide precise measurements of the strains.

\subsection{Thickness ratio of the glazed tiles}

To study the effect of the thickness of glazes and ceramic bodies on the wear resistance of the samples and calculate the stress on the glaze surface, the glaze thicknesses were measured by SEM. Fig. 5 shows the cross-section images of the sample $\mathrm{R}_{07}{ }^{12}$. As the glazed layers had different morphology than the ceramic bodies, these two layers were clearly distinguished; moreover, since the heating process lasted for only $35 \mathrm{~min}$, the gas could not be fully released during this extremely fast process. Although many bubbles existed 


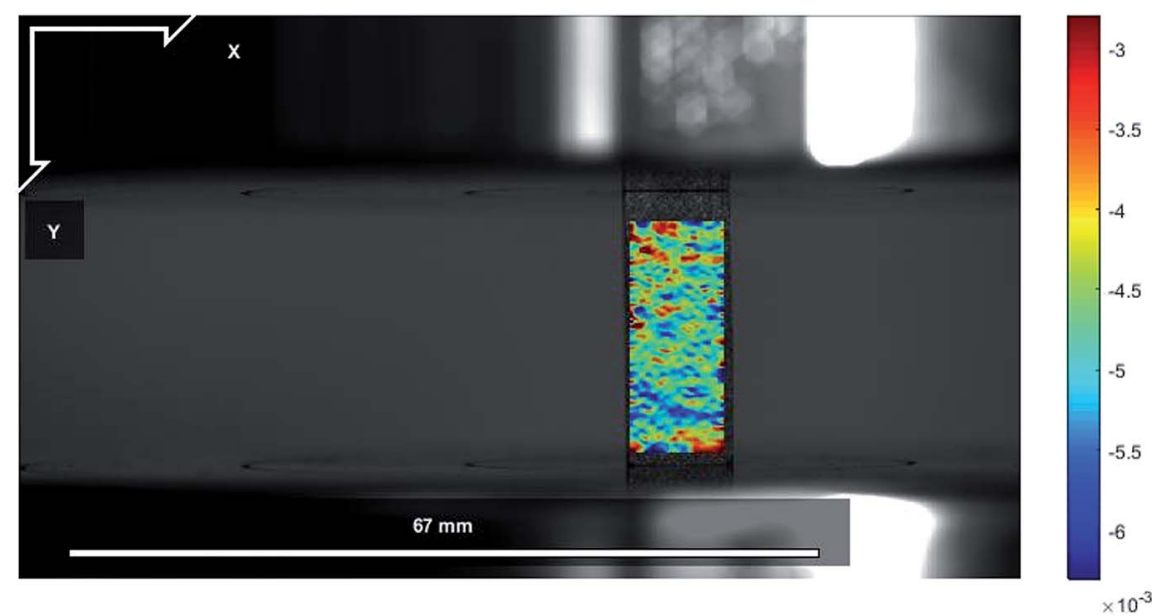

Type: eyy-plot

Reference Name: Body_o.jpg

Current Name: Body_B.jpg

Analysis type: regular

RG-DIC Radius: 36 | Strain Radius: 5 | Subset Spacing: 2

Diffnom Cutoff: $1 \mathrm{e}-00$ | Iteration Cutoff: 50 | Threads: 4

Step Analysis: Disabled

RG-DIC Subset Truncation: Disabled I Strain Subset Truncation: Disabled

Image Correspondences: [0 6]

Unitsipixels: $0.02254 \mathrm{~mm} / \mathrm{pixels}$

Comelation Coefficient Cutoff: $\mathbf{0 . 0 4 3 7}$

Radial Lens Distortion Coefficient: 0

Max: -0.0007 Median: -0.0047| Mín: - 0.0079
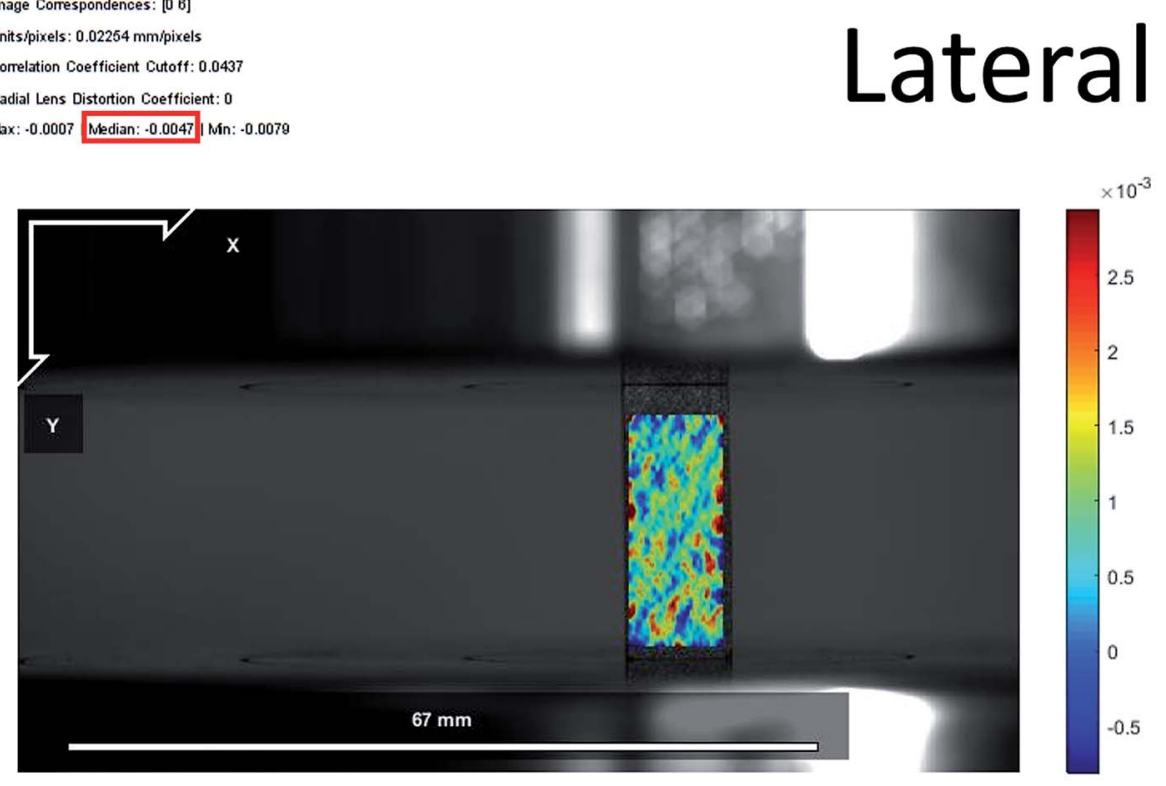

Type: exx-plot

Reference Name: Body_0.jpg

Current Name: Body_ 6 .jpg

Analysis type: regular

RG.DIC Radius: 38 | Strain Radius: 5 | Subset Spacing: 2

Diffnom Cutoff: $1 \mathrm{e}-08$ | Iteration Cutoff: 50 | Threads: 4

Step Analysis: Disabled

RG-DIC Subset Truncation: Disabled I Strain Subset Truncation: Disabled

Image Correspondences: [0 6]

Units/pixels: 0.02254 mmipixels

Correlation Coefficient Cutoff: 0.0437

Radial Lens Distortion Coefficient: 0

Max: 0.0076 | Median: 0.0009 | Min: -0.0041

Fig. 3 The lateral and axial strain data plot of the sample $\mathrm{R}_{0}$ under a $15000 \mathrm{~N}$ compressive loading.

in the samples, as shown in Fig. 5 , the water absorption was less than $0.4 \%$. As shown in Fig. 6, no blowhole defects were observed on the sample surfaces with or without the abrasion test; this indicated that the samples were sufficiently compact to be used for the abrasion test. The thicknesses of the glazes were measured by SEM, and the thicknesses of the sintered glazed tiles were measured 

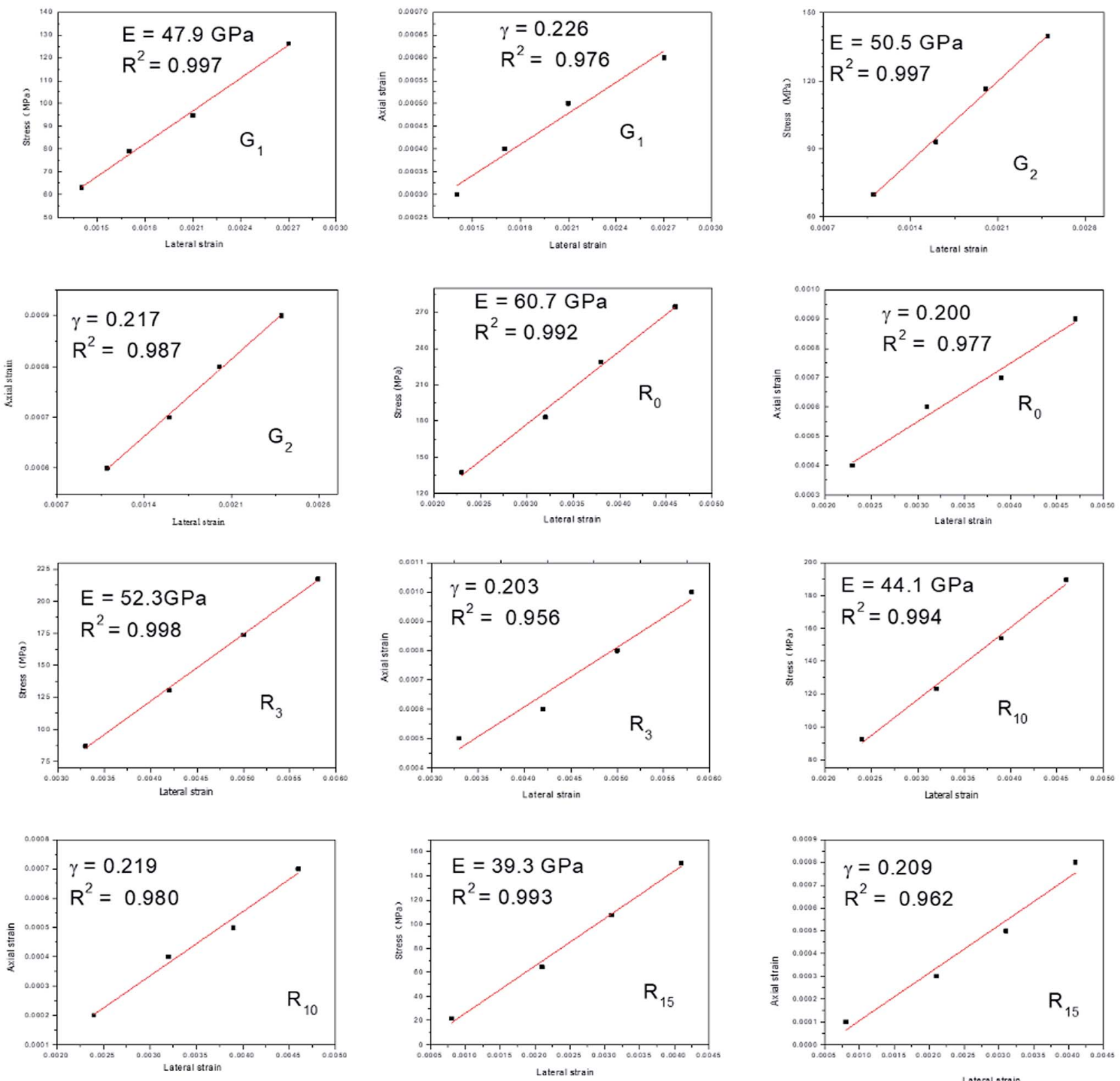

Fig. 4 Stress-strain curves and lateral-axial strain curves of the samples $G_{1}, G_{2}$ and $R_{0}$ to $R_{15}$.

by a micrometer caliper. Via this way, the thickness ratios of the glazed tiles were calculated and are listed in Table 2. Since $\mathrm{G}_{1}$ and $\mathrm{G}_{2}$ have similar components, the $\mathrm{R}-\mathrm{G}_{1}$ and $\mathrm{R}-\mathrm{G}_{2}$ samples have similar glaze thicknesses. Thus, the thickness ratio of these two series was similar to that of the sample $\mathrm{R}_{07}{ }^{10}$.

\subsection{Thermal expansivity of the glazes and ceramic tiles}

Both ceramic bodies and glazes are isotropic materials. The thermal expansivities of the glazes and ceramic bodies are $\alpha_{\mathrm{g}}$ and $\alpha_{\mathrm{b}}$, respectively. Under the condition of $\alpha_{\mathrm{b}}>\alpha_{\mathrm{g}}$, the ceramic body suffers a tension stress, and the glaze suffers a pressure stress. The thermal expansivity investigated in this study was an average value of that obtained in the range from room temperature $\left(25{ }^{\circ} \mathrm{C}\right)$ to $T_{\mathrm{g}}$ of the glaze. After the annealing treatment, the glass network structure of the glaze would become denser without any change in the thermal expansivity; this would lead to a greater expansion of the sample beyond $T_{\mathrm{g}}$ during the heating process than that for the sample without annealing; this phenomenon is expressed as a sudden increase in the slope of the thermal expansion curves. ${ }^{27}$ Thus, the thermal deformation and $T_{\mathrm{g}}$ of the samples could be measured by the thermal expansion curves, as shown in Fig. 7. It was observed that $\mathrm{G}_{1}$ and $\mathrm{G}_{2}$ presented similar thermal deformation behavior, and the $T_{\mathrm{g}}$ values of $\mathrm{G}_{1}$ and $\mathrm{G}_{2}$ were $668^{\circ} \mathrm{C}$ and $645^{\circ} \mathrm{C}$, respectively. Because the degree of densification in $\mathrm{G}_{1}$ might be 


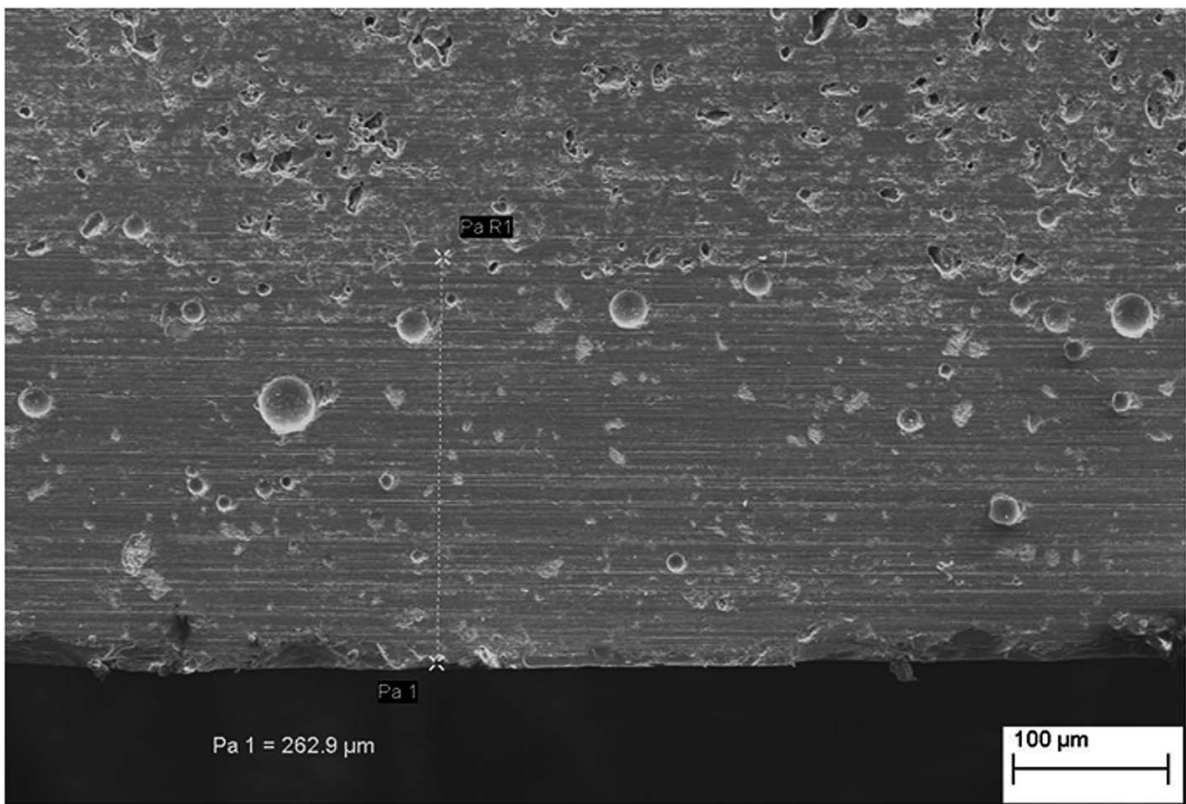

Fig. 5 Cross-section images of the sample $\mathrm{R}_{07}{ }^{12}$

greater than that in $G_{2}$, the slope of the $G_{1}$ curves increased more. To simplify and make the calculation of thermal expansivity uniform, the temperatures used in this study ranged from $640^{\circ} \mathrm{C}$ to $25^{\circ} \mathrm{C}$. The thermal expansivities of the ceramic bodies and glazes are listed in Table 3. Due to its extremely low thermal expansion, fused quartz has been widely used to reduce the thermal expansivity of heated components. Table 3 shows that the addition of fused quartz can significantly reduce the thermal expansivity of ceramic bodies, and the thermal expansivity of ceramic bodies added with $15 \mathrm{wt} \%$ fused quartz is $68 \%$ of that without fused quartz.

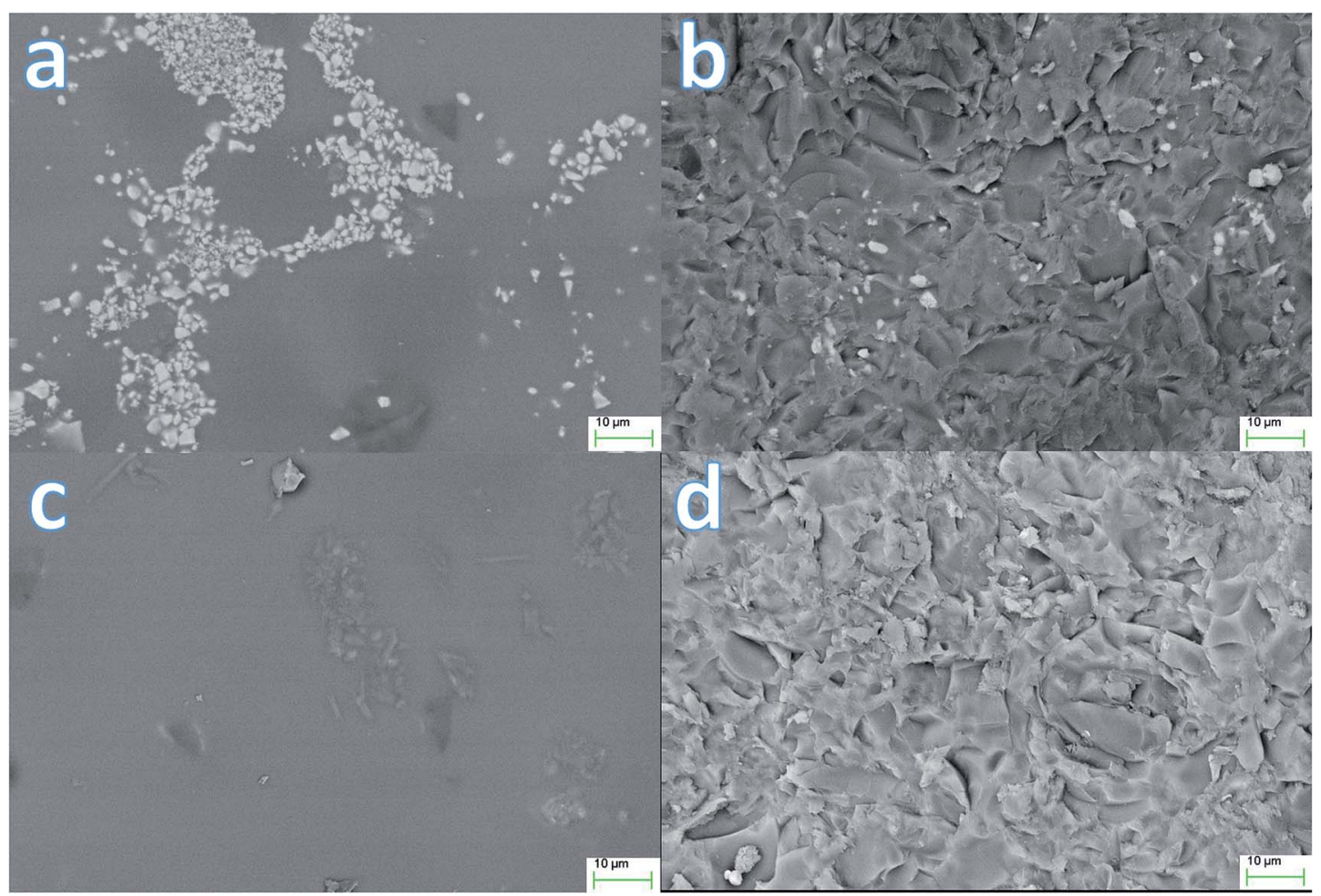

Fig. 6 SEM images of the surfaces of the samples $R_{0}-G_{1}$ and $R_{15}-G_{2}$ ((a) the origin surface of sample $R_{0}-G_{1}$, (b) the abrasion surface of sample $R_{0}$ $G_{1}$, (c) the origin surface of sample $R_{15}-G_{2}$, and (d) the abrasion surface of sample $R_{15}-G_{2}$ ). 
Table 2 The thickness ratios of samples from $\mathrm{R}_{06}{ }^{8}$ to $\mathrm{R}_{08}{ }^{12}$

\begin{tabular}{lllllllll}
\hline Sample & $\mathrm{R}_{08}{ }^{8}$ & $\mathrm{R}_{08}{ }^{10}$ & $\mathrm{R}_{07}{ }^{8}$ & $\mathrm{R}_{06}{ }^{8}$ & $\mathrm{R}_{07}{ }^{10}$ & $\mathrm{R}_{06}{ }^{10}$ & $\mathrm{R}_{08}{ }^{12}$ & $\mathrm{R}_{07}{ }^{12}$ \\
\hline Thickness ratio & 0.018 & 0.024 & 0.025 & 0.026 & 0.028 & 0.033 & 0.039 & 0.040
\end{tabular}

\subsection{The calculation of prestress}

For an infinitely flat-shaped sample, the thickness ratio of the glaze layer to the green body layer can be denoted as $j$. During the cooling process, when the temperature is lower than the glaze temperature $\left(T_{\mathrm{g}}\right)$, both the glaze and the green body contract as the temperature decreases. In the absence of an external force, the contraction of the glaze differs from that of the ceramic. However, as they are bonded together and cannot contract freely, both the stress $\sigma_{\mathrm{g}}$ (for glaze) and $\sigma_{\mathrm{b}}$ (for the ceramic body) are experienced, resulting in the shrinking of the glaze and ceramic body at the same rate throughout the cooling process. Since the thermal expansivity of the ceramic body is larger than that of the glaze, $\sigma_{\mathrm{g}}$ is the pressure stress and $\sigma_{\mathrm{b}}$ is the tensile stress; moreover, the difference between the temperature of the glaze $T_{\mathrm{g}}$ and the natural surrounding temperature is named $\Delta T$. Eqn (1) can be obtained by the static balance condition:

$$
\sigma_{\mathrm{g}}=\frac{\sigma_{\mathrm{b}}}{j}
$$

As glaze and ceramic experience the same contraction, it can be derived that

$$
\begin{aligned}
& \Delta_{\mathrm{g}}=\alpha_{\mathrm{g}} \Delta T l+\frac{\sigma_{\mathrm{g}}}{E_{\mathrm{g}}}\left(1-\mu_{\mathrm{g}}\right) l \\
& \Delta_{\mathrm{b}}=\alpha_{\mathrm{b}} \Delta T l-\frac{\sigma_{\mathrm{b}}}{E_{\mathrm{b}}}\left(1-\mu_{\mathrm{b}}\right) l
\end{aligned}
$$

Table 3 Thermal expansivity of the ceramic bodies and glazes from $640{ }^{\circ} \mathrm{C}$ to $25^{\circ} \mathrm{C}$

\begin{tabular}{ll}
\hline Sample & Thermal expansivity $\left(\times 10^{-6}{ }^{\circ} \mathrm{C}^{-1}\right)$ \\
\hline $\mathrm{R}_{0}$ & 8.9 \\
$\mathrm{R}_{3}$ & 8.6 \\
$\mathrm{R}_{10}$ & 7.9 \\
$\mathrm{R}_{15}$ & 6.8 \\
$\mathrm{G}_{1}$ & 6.5 \\
$\mathrm{G}_{2}$ & 7.7
\end{tabular}

Table 4 Surface stress and abrasion weight loss after abrasion wear of $\mathrm{G}_{1}$ and $\mathrm{G}_{2}$ glazing on $\mathrm{R}_{0}, \mathrm{R}_{3}, \mathrm{R}_{10}$ and $\mathrm{R}_{15}$

\begin{tabular}{lcc}
\hline Sample & Weight loss $(\mathrm{mg})$ & $\begin{array}{l}\text { Pressure stress } \\
(\mathrm{MPa})\end{array}$ \\
\hline $\mathrm{R}_{0}-\mathrm{G}_{1}$ & $99.2 \pm 2.0$ & 89.3 \\
$\mathrm{R}_{3}-\mathrm{G}_{1}$ & $105.4 \pm 4.4$ & 77.9 \\
$\mathrm{R}_{10}-\mathrm{G}_{1}$ & $109.7 \pm 1.7$ & 51.7 \\
$\mathrm{R}_{15}-\mathrm{G}_{1}$ & $113.5 \pm 0.5$ & 11.0 \\
- & - & - \\
$\mathrm{R}_{0}-\mathrm{G}_{2}$ & $137.2 \pm 1.2$ & 46.4 \\
$\mathrm{R}_{3}-\mathrm{G}_{2}$ & $146.3 \pm 3.1$ & 34.7 \\
$\mathrm{R}_{10}-\mathrm{G}_{2}$ & $154.3 \pm 4.5$ & 7.7 \\
$\mathrm{R}_{15}-\mathrm{G}_{2}$ & $161.4 \pm 3.5$ & -34.4
\end{tabular}

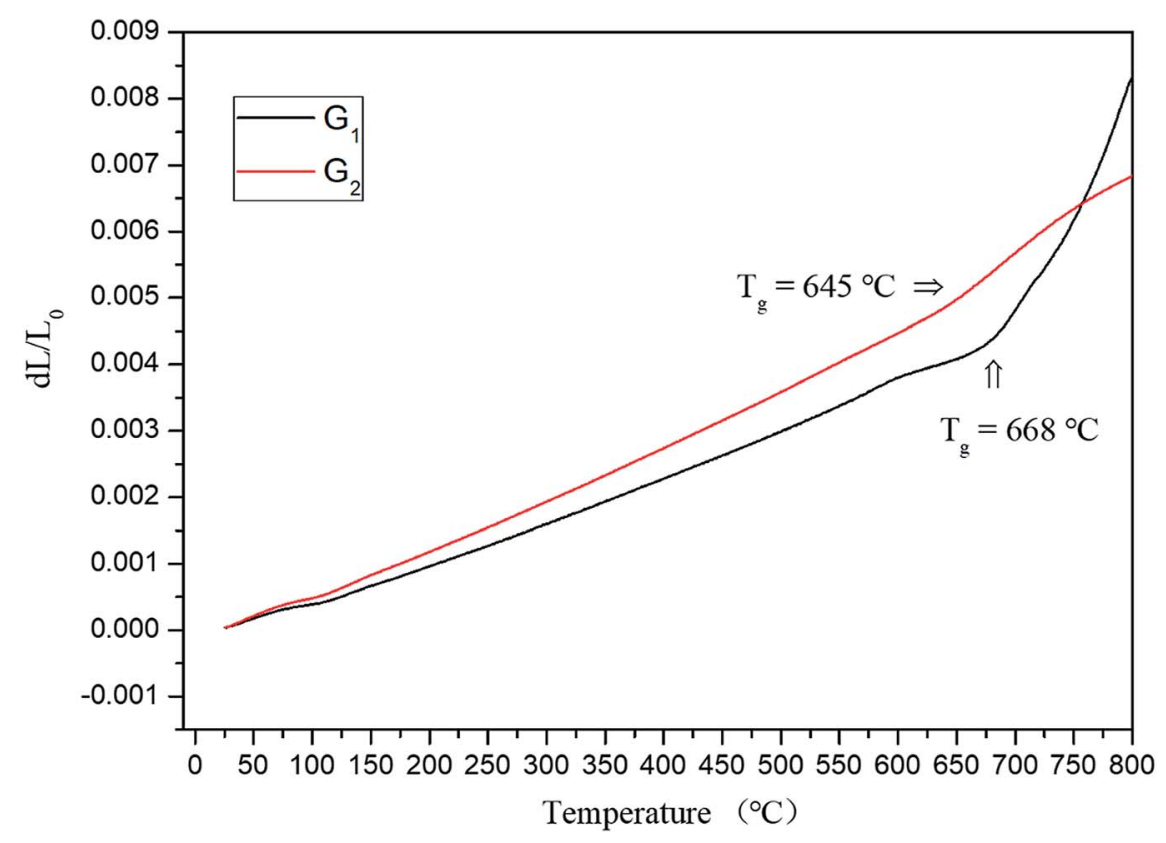

Fig. 7 Thermal expansion curves of $G_{1}$ and $G_{2}$. 
Table 5 Surface stress and abrasion weight loss after abrasion wear of the $\mathrm{G}_{2}$ glazed tiles with different thickness ratios

\begin{tabular}{llll}
\hline Sample & $\begin{array}{l}\text { Thickness } \\
\text { ratio }\end{array}$ & Weight loss $(\mathrm{mg})$ & $\begin{array}{l}\text { Pressure stress } \\
(\mathrm{MPa})\end{array}$ \\
\hline $\mathrm{R}_{08}{ }^{8}$ & 0.018 & $130.3 \pm 1.7$ & 46.8 \\
$\mathrm{R}_{08}{ }^{10}$ & 0.024 & $134.0 \pm 1.4$ & 46.6 \\
$\mathrm{R}_{07}{ }^{8}$ & 0.025 & $134.6 \pm 0.6$ & 46.5 \\
$\mathrm{R}_{06}{ }^{8}$ & 0.026 & $139.6 \pm 0.8$ & 46.5 \\
$\mathrm{R}_{07}{ }^{10}$ & 0.028 & $137.2 \pm 1.2$ & 46.4 \\
$\mathrm{R}_{06}{ }^{10}$ & 0.033 & $143.2 \pm 0.2$ & 46.2 \\
$\mathrm{R}_{08}{ }^{12}$ & 0.039 & $142.4 \pm 1.4$ & 46.0 \\
$\mathrm{R}_{07}{ }^{12}$ & 0.040 & $143.7 \pm 0.9$ & 46.0 \\
$\mathrm{R}_{06}{ }^{12}$ & 0.043 & $146.0 \pm 0.2$ & 45.9 \\
& & &
\end{tabular}

$$
\Delta_{\mathrm{g}}=\Delta_{\mathrm{b}}
$$

where $E_{\mathrm{g}}$ and $E_{\mathrm{b}}$ denote the elastic moduli of the glaze and ceramic body (MPa), respectively; $\mu_{\mathrm{g}}$ and $\mu_{\mathrm{b}}$ denote the Poisson's ratio of the glaze and ceramic, respectively; and $l$ is the length of the glazed tile ( $\mathrm{mm})$.

Thus, the pressure stress of the glaze can be derived using eqn (1)-(4):

$$
\sigma_{\mathrm{g}}=\frac{\left(\alpha_{\mathrm{b}}-\alpha_{\mathrm{g}}\right) \Delta T}{\frac{1-\mu_{\mathrm{g}}}{E_{\mathrm{g}}}+j \frac{1-\mu_{\mathrm{b}}}{E_{\mathrm{b}}}}
$$

\subsection{The effect of prestress and zircon grains}

The abrasion weight loss of $G_{1}$ and $G_{2}$ glazing on four kinds of ceramic bodies and the stresses of each sample calculated through eqn (5) are listed in Table 4. Eqn (5) shows that when the thermal expansivity of the ceramic body is greater than that of glaze, the pressure stress that the glaze suffers is stronger. $\mathrm{R}_{0}$ possessed highest thermal expansivity, and $\mathrm{R}_{15}$ possessed lowest thermal expansivity. Thus, $R_{0}-G_{1}$ and $R_{0}-G_{2}$ possessed strongest pressure stresses, whereas $R_{15}-G_{1}$ and $R_{15}-G_{2}$ possessed weakest pressure stresses in the $G_{1}$ and $G_{2}$ sample series, respectively. Because the thermal expansivity of $R_{15}$ was lower than that of $G_{2}$, the sample $R_{15}-G_{2}$ suffered tensile stress, which could be defined as a negative value of pressure stress. Moreover, with an increase in the pressure stresses of the glazes, the weight losses of the samples diminished accordingly; this was attributed to the stronger wear resistance performance. Regardless of whether wear-resistance grains (in this study, zircon) were included in the glazes, the pressure stress could enhance the wear resistance of the glazed tiles, and the reinforcement effect of the zircon grains was more effective than prestress. In this study, the gains in wear resistance contributed by the pressure stress were $14.4 \%$ and $17.6 \%$ for $G_{1}$ and $G_{2}$, respectively. Although the pressure stresses of the samples $R_{15}$ $\mathrm{G}_{1}$ and $\mathrm{R}_{10}-\mathrm{G}_{2}$ were similar and close to those of the stress-free samples, the abrasion weight loss of the former was $35.9 \%$ less than that of the latter, respectively, due to the addition of $7.2 \mathrm{wt} \%$ zircon grains. Compared with that of the sample $\mathrm{R}_{15}$ $\mathrm{G}_{2}$, the weight loss of the sample $\mathrm{R}_{0}-\mathrm{G}_{1}$ decreased by $62.7 \%$ due to the introduction of the zircon grains $(7.2 \mathrm{wt} \%)$ and preloading of a high pressure stress (123.7 MPa).

\subsection{Effect of the thickness of glaze and body}

Table 5 lists the abrasion weight losses and the calculated stresses of $\mathrm{G}_{2}$ glazed tiles with different thickness ratios (glaze/ body). The results suggested that the effect of the thickness ratio on the stress suffered by the glaze was significantly weaker

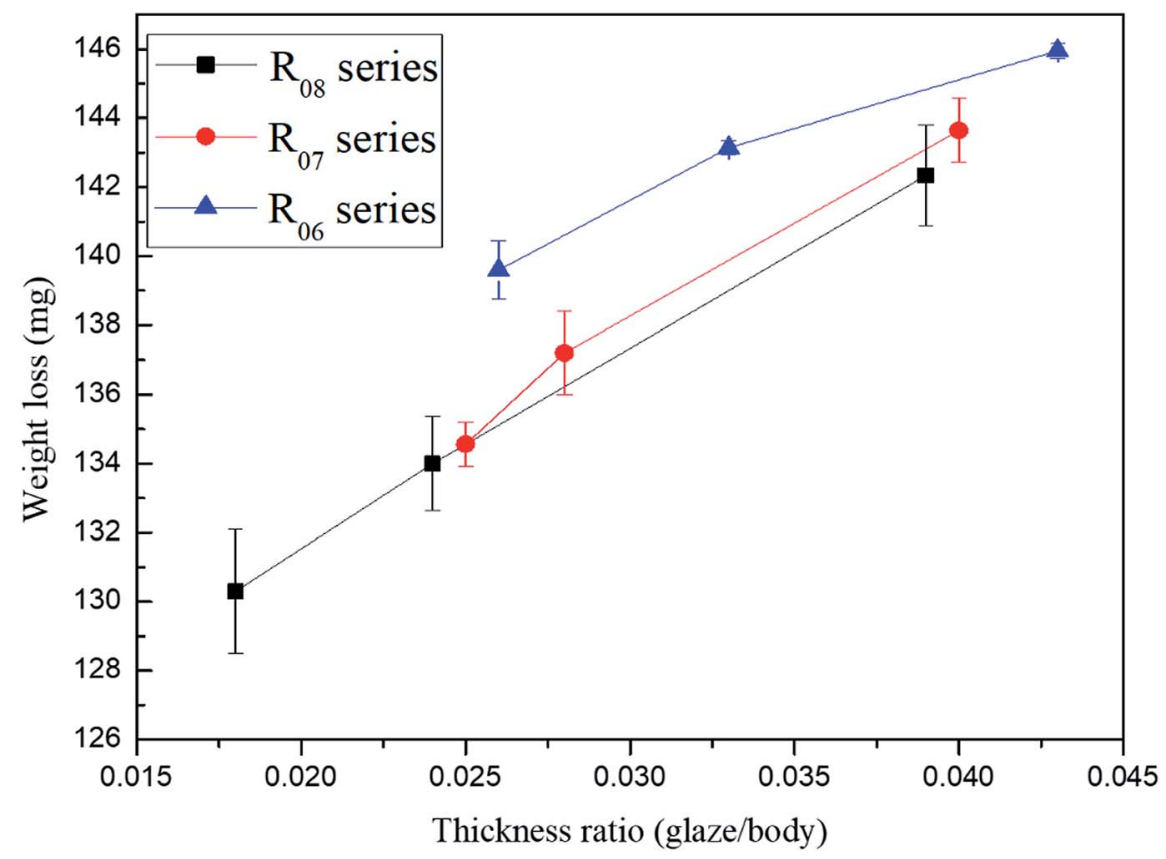

Fig. 8 The average weight loss of the $R_{06}, R_{07}$ and $R_{08}$ series $G_{2}$ glazed tiles with different thickness ratios. 

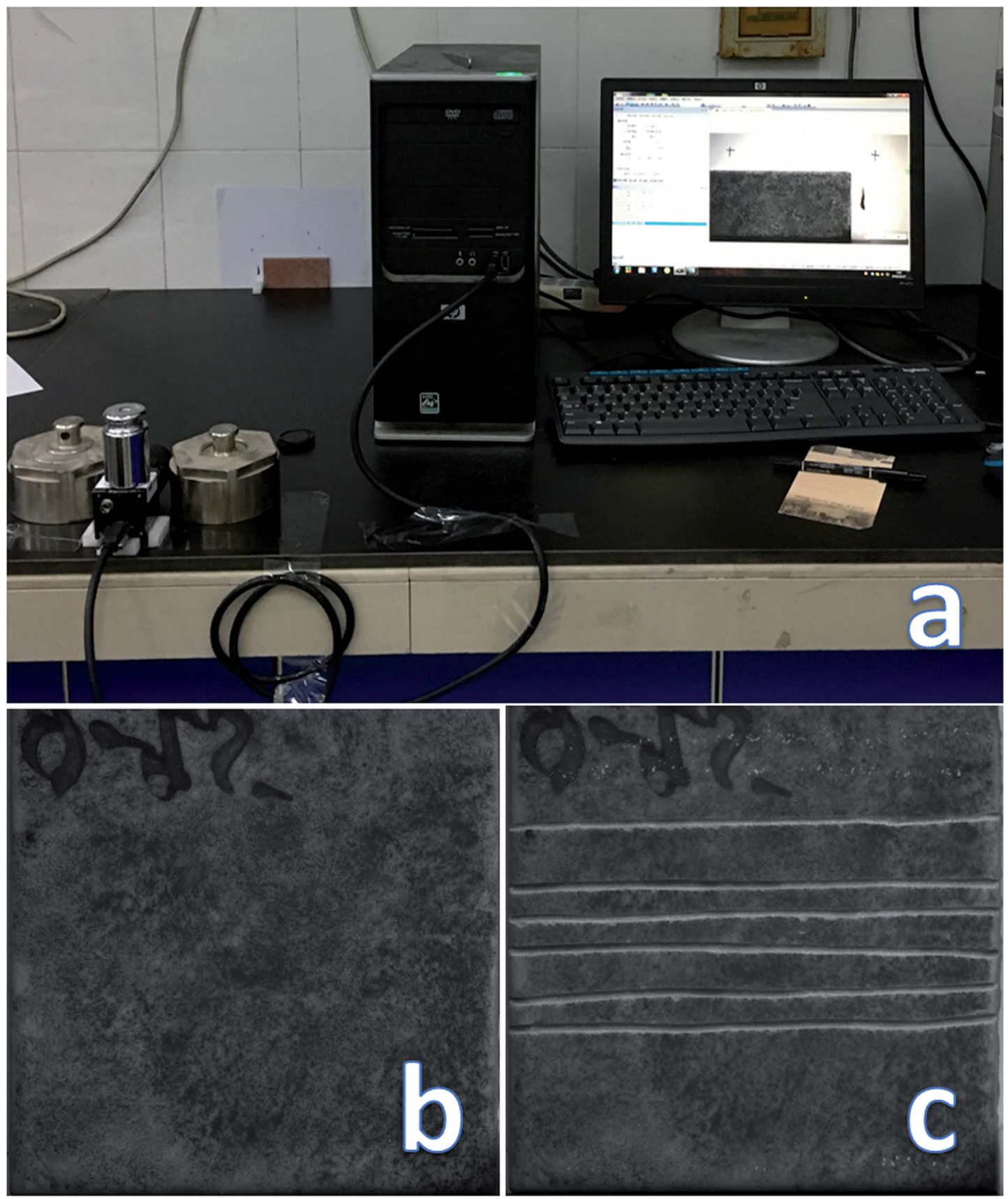

Fig. 9 The 2D-DIC system and sample surface images ((a) DIC system, (b) initial surface of sample, and (c) strip-cutting destruction surface of sample).

than the effects of thermal expansion when compared with the results presented in Table 4. Furthermore, the relationship between the glaze thicknesses and the abrasion weight losses of the $R_{06}, R_{07}$ and $R_{08}$ series samples is shown in Fig. 8. For the samples with the same ceramic body thickness (approximately 6 $\mathrm{mm}, 7 \mathrm{~mm}$ or $8 \mathrm{~mm}$ ), an increase in the glaze thickness led to an increase in the weight loss of the samples; this indicated a relatively weaker wear resistance capacity. Moreover, for the glazed tiles with glaze layers of similar thickness, an increase in the thickness of the ceramic bodies would enhance their wear resistance. A glazed tile may undergo deformation during the cooling process due to the different contractions of the glaze and ceramic body. This deformation of the glazed tiles causes a structural adjustment in the glaze-ceramic body, and the actual value of the pressure stress may be less than the calculated value. A thicker ceramic body or thinner glaze layer may lead to a weaker deformation of the glazed tiles; thus, the value of the pressure stress is more consistent with the ideal model. In this study, the sample $\mathrm{R}_{08}{ }^{8}$ had the thickest ceramic body layer, the thinnest glaze layer and the highest pressure stress among the sample $G_{2}$ series, and the abrasion weight loss of $\mathrm{R}_{08}{ }^{8}$ was $23.9 \%$ less than that of $\mathrm{R}_{15}-\mathrm{G}_{2}$. 

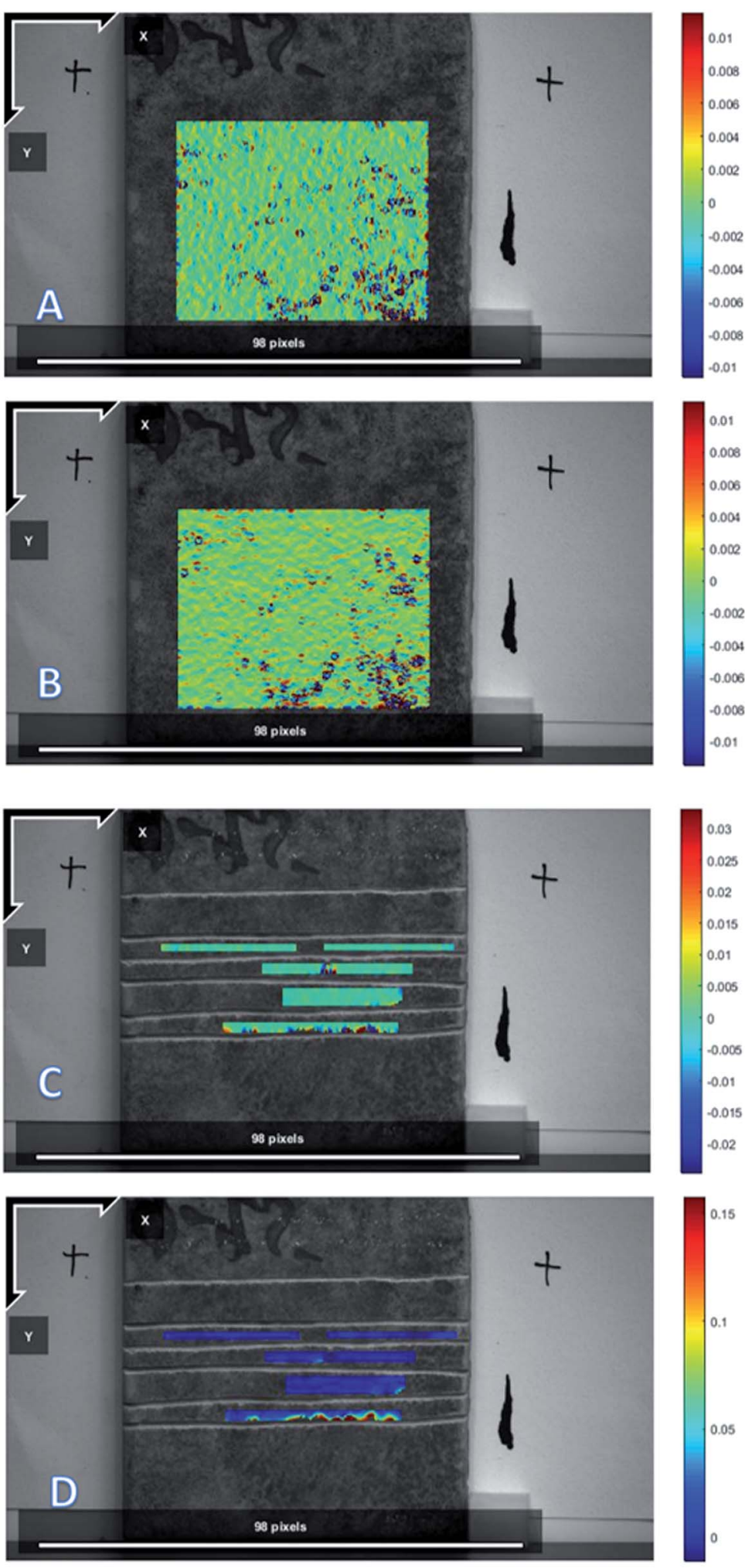

Type: exx-plot

Reference Name: Tile_0.jpg

Current Name: Tile_2.jpg

Analysis type: regular

RG.DIC Radius: 21 | Strain Radius: 5 | Subset Spacing: 1

Diffnom Cutoff: 1e. 06 | Iteration Cutoff: 50 | Threads: 4

Step Analysis: Disabled

RQ.DIC Subset Truncation: Disabled I Strain Subset Truncation: Disabled

Image Correspondences: [0 1]

Units/pixels: 0.033 pixels/pixels

Correlation Coefficient Cutoff: 0.8000

Radial Lens Distortion Coefficient: 0

Max: 0.1082 | Median: 0.0002 | Mn: -0.1409

Type: eyry.plot

Reference Name: Tile_0.jpg

Current Name: Tile_2.jpg

Analysis type: regular

RG-DIC Radius: 21 | Strain Radius: 6 | Subset Spacing: 1

Diffnorm Cutoff: 1 e. 00 | Iteration Cutoff: 60 । Threads: 4

Step Analysis: Disabled

RG.DIC Subset Truncation: Disabled I Strain Subset Truneation: Disabled

Image Correspondences: [0 $\left[\begin{array}{ll}0 & 1\end{array}\right]$

Units/pixels: 0.033 pixelsipixels

Correlation Coefficient Cutoff: 0.8000

Radial Lens Distortion Coefficient: 0

Max: 0.1297 | Median: 0.0003 | Mn: -0.2080

Type: exx-plot

Reference Name: Tie5_0.jpg

Current Name: Tie5_1.jpg

Analysis type: regular

RG-DIC Radius: 36 | Strain Radius: 6 | Subset Spacing: 3

Diffnorm Cutoff: 1e. 00 | Iteration Cutoff: 50 | Threads: 4

Step Analysis: Disabled

RG-DIC Subset Truncation: Disabled I Strain Subset Trunoation: Disabled

Image Correspondences: [0 1]

Units/pixels: 0.033 pixels/pixels

Correlation Coefficient Cutoff: 1.7071

Radial Lens Distortion Coefficient: 0

Max: 0.1926 I Median: 0.0000 I Mn: -0.2052

Type: eyy-plot

Reference Name: Tie5_0.jpg

Current Name: Tie5_1.jpg

Analysis type: regular

RG.DIC Radius: 36 | Strain Radius: 5 | Subset Spacing: 3

Diffnorm Cutoff: 1e. 06 | Iteration Cutoft: 50 | Threads: 4

Step Analysis: Disabled

RG.DIC Subset Truncation: Disabled I Strain Subset Trunoation: Disabled

Image Correspondences: $\left[\begin{array}{ll}0 & 1\end{array}\right]$

Units/pixels: 0.033 pixels/pixels

Correlation Coefficient Cutoff: 1.7071

Radial Lens Distortion Coefficient: 0

Max: 0.4856 | Median: 0.0010 | Mn: -0.0360

Fig. 10 Sample strain analysis results ((A) $X$-axis strain diagram after annealing; (B) $Y$-axis strain diagram after annealing; (C) $X$-axis strain diagram after strip-cutting destruction; and (D) $Y$-axis strain diagram after strip-cutting destruction).

\subsection{Prestress measurement}

Fig. 9 shows the optical images of the 2D-DIC measurement platform and the initial and post-treatment state of the sample.
By fixing the position of the camera as well as the sample, not only could the stability of the test be guaranteed, but also the strain field prior to and after the sample processing could be 
obtained through the 2D-DIC analysis, whose results are shown in Fig. 10. After the annealing treatment, the tempering stress on the surface of the samples was virtually eliminated. Therefore, the strains caused by annealing appeared in the directions of the $X$ axis and $Y$ axis, whose figures were 0.0002 and 0.0003 , respectively. Since the strip cutting process is only helpful to release the stress in the direction normal to the strip, the experimental strip direction was parallel to the $X$ axis. Therefore, no strain was detected in the $X$ axis direction after the slitting processing, whereas the large strain of 0.0010 was generated in the $Y$-axis direction. The results show that the sample suffered both the tempering stress and shrinkage stress during the cooling process; based on the elastic modulus of the glaze, the tempering stress was calculated to be 10.1-15.2 MPa, and the shrinkage stress was $50.5 \mathrm{MPa}$; these values were close to the results obtained from the simulation calculations.

\section{Conclusion}

(1) The elastic modulus and Poisson ratio of the glaze and ceramic bodies can be accurately, conveniently and efficiently measured by a 2D-DIC system. The prestress of the glaze can then be calculated according the double-layer thermal residual stress model. The stress of the glazed tile can be measured by this 2D-DIC system combined with the stress-release method.

(2) A greater thermal expansivity difference or a lower thickness ratio between the glaze and the ceramic body can enhance the wear resistance of the glaze by providing a stronger pressure stress to the glaze or reducing the deformation of the glazed tile, respectively. As the thermal expansivity of the ceramic body increased from $6.8 \times 10^{-6}{ }^{\circ} \mathrm{C}^{-1}$ to $8.9 \times 10^{-6}{ }^{\circ} \mathrm{C}^{-1}$ and the thickness ratio of the $\mathrm{G}_{2}$ glazed tile decreased from 0.043 to 0.018 , the calculated pressure stress of the $\mathrm{G}_{2}$ glazed tiles was increased by $81.2 \mathrm{MPa}$, and the abrasive weight loss of the glazed tiles was reduced by $23.9 \%$.

(3) Glaze wear resistance can be effectively reinforced by compositely introducing hard grains and prestress. In this study, compared with the cases of the samples $R_{0}-G_{1}$ and $R_{15}-G_{2}$, the addition of a $123.7 \mathrm{MPa}$ prestress and $7.2 \mathrm{wt} \%$ zircon resulted in the reduction of the glaze abrasive weight loss by $62.7 \%$.

\section{Conflicts of interest}

There are no conflicts to declare.

\section{Acknowledgements}

This work was financially supported by the National Natural Science Foundation of China (Grant No. B5141540).

\section{References}

1 L. Fröberg, et al., Chemical durability of glazed surfaces, $J$. Eur. Ceram. Soc., 2007, 27(2), 1811-1816.

2 L. Hupa, et al., Chemical resistance and cleanability of glazed surfaces, Surf. Sci., 2005, 584(1), 113-118.
3 M. Piispanen, et al., Chemical resistance and cleaning properties of coated glazed surfaces, J. Eur. Ceram. Soc., 2009, 29(10), 1855-1860.

4 J. Määttä, et al., Effect of coating on cleanability of glazed surfaces, J. Eur. Ceram. Soc., 2007, 27(16), 4555-4560.

5 R. Kuisma, et al., Microstructure and cleanability of uncoated and fluoropolymer, zirconia and titania coated ceramic glazed surfaces, J. Eur. Ceram. Soc., 2007, 27(1), 101-108.

6 E. Barrachina, et al., Development of a glass-ceramic glaze formulated from industrial residues to improve the mechanical properties of the porcelain stoneware tiles, Mater. Lett., 2018, 220, 226-228.

7 M. Sheikhattar, H. Attar, S. Sharafi, et al., Influence of surface crystallinity on the surface roughness of different ceramic glazes, Mater. Charact., 2016, 118, 570-574.

8 A. Viat, M. De Barros Bouchet, B. Vacher, et al., Nanocrystalline glaze layer in ceramic-metallic interface under fretting wear, Surf. Coat. Technol., 2016, 308, 307-315.

9 G. Topateş, B. Tarhan and M. Tarhan, Chemical durability of zircon containing glass-ceramic glazes, Ceram. Int., 2017, 43(15), 12333-12337.

10 M. Leśniak, J. Partyka and M. Sitarz, Impact of ZnO on the structure of aluminosilicate glazes, J. Mol. Struct., 2016, 1126, 251-258.

11 Y. Abouliatim, et al., Study of borosilicate glaze opacification by phosphates using Kubelka-Munk model, Ceram. Int., 2017, 43(8), 5862-5869.

12 B. Karasu, E. Dölekçekiç and B. Özdemir, Compositional modifications to floor tile glazes opacified with zircon, $\mathrm{Br}$. Ceram. Trans., 2013, 100(2), 81-85.

13 R. J. Castilone, D. Sriram, W. M. Carty, et al., Crystallization of Zircon in Stoneware Glazes, J. Am. Ceram. Soc., 1999, 82(10), 2819-2824.

14 I. L. Aurélio, L. S. Dorneles and L. G. May, Extended glaze firing on ceramics for hard machining: Crack healing, residual stresses, optical and microstructural aspects, Dent. Mater., 2017, 33(2), 226-240.

15 S. Ghosh, K. S. Pal, N. Dandapat, et al., Glass-ceramic glazes for future generation floor tiles, J. Eur. Ceram. Soc., 2013, 33(5), 935-942.

16 S. Wang, C. Peng, H. Xiao, et al., Microstructural evolution and crystallization mechanism of zircon from frit glaze, $J$. Eur. Ceram. Soc., 2015, 35(9), 2671-2678.

17 E. Bou, A. Moreno, A. Escardino, et al., Microstructural study of opaque glazes obtained from frits of the system: $\mathrm{SiO}_{2}$ $\mathrm{Al}_{2} \mathrm{O}_{3}-\mathrm{B}_{2} \mathrm{O}_{3}-\left(\mathrm{P}_{2} \mathrm{O}_{5}\right)-\mathrm{CaO}-\mathrm{K}_{2} \mathrm{O}-\mathrm{TiO}_{2}$, J. Eur. Ceram. Soc., 2007, 27(2-3), 1791-1796.

18 M. Llusar, C. Rodrigues, J. Labrincha, et al., Reinforcement of single-firing ceramic glazes with the addition of polycrystalline tetragonal zirconia (3Y-TZP) or zircon, $J$. Eur. Ceram. Soc., 2002, 22(5), 639-652.

19 T. Murakami, et al., Zirconia surface modification by a novel zirconia bonding system and its adhesion mechanism, Dent. Mater., 2017, 33(12), 1371-1380. 
20 L. Kurpaska, Structural properties of zirconia-in situ high temperature XRD characterization, J. Mol. Struct., 2018, 1163, 287-293.

21 A. Koike, et al., Difference of cracking behavior due to Vickers indentation between physically and chemically tempered glasses, J. Non-Cryst. Solids, 2012, 358(24), 34383444.

22 C. L. Shepard, B. D. Cannon and M. A. Khaleel, Measurement of Internal Stress in Glass Articles, J. Am. Ceram. Soc., 2010, 86(8), 1353-1359.

23 BS ISO 19603-2016, Fine ceramics (advanced ceramics, advanced technical ceramics), Test method for determining elastic modulus and bending strength of thick ceramic coatings.
24 ASTM E1876-01(2006), Standard Test Method for Dynamic Young's Modulus, Shear Modulus, and Poisson's Ratio by Impulse Excitation of Vibration.

25 I. A. Lima Neto, M. A. R. Ceia, R. M. Misságia, G. L. P. Oliveira, V. H. Santos, R. P. R. Paranhos and N. L. Archilha, Testing and evaluation of 2D/3D digital image analysis methods and inclusion theory for microporosity and S-wave prediction in carbonates, Mar. Pet. Geol., 2018, 97, 592-611.

26 M. A. Sutton and F. Hild, Recent Advances and Perspectives in Digital Image Correlation, Exp. Mech., 2015, 55(1), 1-8.

27 W. D. Kingery, H. K. Bowen and D. R. Uhlmann, Introduction To Ceramics, Wiley, New York, NY, USA, 2nd edn, 1976. 